\title{
SONOLOGICAL EVALUATION OF SOLITARY THYROID NODULES TO PREDICT BENIGN OR MALIGNANT NATURE: A STUDY IN A RURAL TERTIARY CARE HOSPITAL IN SOUTH INDIA
}

Madhavi Chamarthi ${ }^{1}$, Abhilash S2, G.S. Kejriwal ${ }^{3}$

HOW TO CITE THIS ARTICLE:

Madhavi Chamarthi, Abhilash S, G.S. Kejriwal. "Sonological Evaluation of Solitary Thyroid Nodules to Predict Benign or Malignant Nature: A Study in a Rural Tertiary Care Hospital in South India". Journal of Evolution of Medical and Dental Sciences 2014; Vol. 3, Issue 09, March 03; Page: 2108-2114,

DOI: $10.14260 /$ jemds/2014/2111

OBJECTIVE: The purpose of this study was to assess the diagnostic accuracy of high frequency Ultrasonography to differentiate the benign and malignant thyroid nodules and to correlate the sonological findings with cytopathological diagnosis. Individual sonological criteria to indicate the malignant nature of a nodule are discussed. MATERIALS AND METHODS: This was a retrospective study done between January, 2012 and November, 2013 in the Department of Radio-diagnosis at Maharajah's Institute of Medical Sciences, Nellimerla, Andhra Pradesh. A total of 180 patients with solitary nodule proved on ultrasonography, followed by ultrasound guided fine needle aspiration (FNA) were included in our study. The sonological characteristics of nodules studied were size, shape, margins, echogenicity, calcification, internal composition, presence or absence of peripheral hallow and vascularity pattern. The results were compared to cytopathological findings. RESULTS: Among the 180 nodules examined, 135 nodules (75\%) were proved to be benign and 45 nodules (25\%) were proved to be malignant. Patients belonging to all age groups were seen with a clear female preponderance. CONCLUSION: High frequency ultrasound is of great value in characterization and differentiation of benign and malignant nodules. It can be successfully used as a guideline to select the patients for fine needle aspiration, in case of suspicious malignant nodule. The sonological criteria favoring malignancy are irregular margins, hypoechogenicity, taller than wide shape, microcalcifications and internal vascularity. The combination of multiple parameters increases the predictive value of ultrasonography.

KEYWORDS: Solitary thyroid nodule, High frequency ultrasonography, Benign, Malignant.

INTRODUCTION: The prevalence of palpable thyroid nodules in general population ranges from 4 to $7 \%$, whereas their prevalence on ultrasonography is as high as $13-67 \%^{1}$. The clinical importance of thyroid nodule relies on the fact that approximately 5 to $25 \%$ of these nodules are malignant, according to different surveys ${ }^{2}$. The goal of diagnostic work up is to detect these patients with malignant nodule, who need surgery. High resolution ultrasound has become the gold standard imaging modality in the evaluation of thyroid nodule. A number of studies were done in literature to determine the efficacy of ultrasound in characterization of nodules as benign or malignant. We conducted a retrospective study to assess the spectrum of sonological appearances of thyroid nodules in our local population. Sonological criteria to detect the malignant nature of thyroid nodules were revisited and their individual sensitivity and specificity were calculated, according to our findings.

MATERIALS AND METHODS: This is a retrospective study carried out at Maharajah's institute of medical sciences, Nellimarla, Andhra Pradesh, India. This study included 180 patients referred from Surgery, ENT and medical outpatient departments with solitary or dominant thyroid nodules. 
The age range of patients is from 8 to 68 years. Of these 180 patients, 24 patients were males and 156 patients were females. Patients with solitary or dominant nodule on ultrasound were included in this study. Exclusion criteria were diffuse goiter and multinodular disease of thyroid. The nodule for which a tissue diagnosis is not obtained, were not included in this study. Thorough history and clinical examination findings were taken for all the patients.

All the patients were subjected to ultrasound examination of thyroid on Philips Envisor or Philips HD7 equipment with 3 to $12 \mathrm{MHZ}$ linear transducer. The criteria for assessment of thyroid nodules used in our study were size, margins, shape, echogenicity, internal composition, calcifications, peripheral halo and internal vascularity.

Size of the nodule is recorded as the greatest diameter of the nodule. The margins are described as well-defined when entire margin is visualized and as ill defined, when more than $50 \%$ of the margin could not be clearly delineated ${ }^{3}$, 4 Shape is assessed by noting the relative proportions of all diameters. Especially the antero-posterior and transverse diameters are noted on a transverse axis scan. Echogenicity is described as hypo, iso or hyperechogenicity, when compared to background gland parenchymal echo texture. Internal composition is described as completely solid, predominantly solid (more than 50\% solid), predominantly cystic (more than $50 \%$ cystic) or completely cystic ${ }^{5}$. Calcifications were classified as micro or macrocalcifications 6 . Peripheral halo was said to be present if it was along the entire margin of nodule and absent or incomplete, when it was along less than $50 \%$ of margin of nodule 7 . Vascularity was described as 4 types from type I to type IV8. (Figures 1, 2, 3, 4, 5 \& 6)

Ultrasound guided FNA was done for all nodules, except purely cystic nodules and cytopathological diagnosis was obtained, which was considered as the final diagnosis. Tissue was obtained by either non-aspiration capillary action technique or suction aspiration technique, depending on vascularity of the nodule.

RESULTS: One hundred and eighty patients with solitary or dominant nodule of thyroid were included in this study. The mean age of patients in our study was 36.2 years. Maximum number of patients $(81.6 \%)$ presented in $3^{\text {rd }}, 4^{\text {th }}$ and $5^{\text {th }}$ decades. The distribution of pathology was independent of age in our study. (Table I)

The nodules were divided into three categories depending on size. The three categories were nodules of less than $1 \mathrm{~cm}$ size, nodules of 1 to $2 \mathrm{~cm}$ size and nodules more than $2 \mathrm{~cm}$ size (Table II).

In this study male to female ratio is $1: 7$, with $13 \%$ male patients and $87 \%$ female patients. In this total study, benign nodules accounted for $75 \%$ of patients and malignant nodules accounted for $25 \%$ of cases. The different pathological causes encountered were nodular goiter, follicular adenoma, lymphocytic thyroiditis, abscess, papillary carcinoma, follicular carcinoma and lymphoma. (Table III \& IV).

DISCUSSION: Solitary thyroid nodule can be defined as a discrete swelling in an otherwise normal, impalpable gland ${ }^{3}$. The significance of thyroid nodules is because of the malignant potential of few nodules. The risk of malignancy in thyroid nodules is usually less than $7 \%$, but can reach upto $20 \%$ in few studies 4,5 . The incidence of malignant nodules in our study is $25 \%$. In this study, among all the benign causes, nodular goiter was the commonest cause of solitary nodule, followed by follicular adenoma, thyroiditis and abscess in reducing order of frequency. Of the malignant causes, papillary 
carcinoma is the most common cause of solitary nodule of thyroid, the other causes being follicular carcinoma, medullary carcinoma and lymphoma.

Physical examination is inaccurate in detection of thyroid nodules, particularly in case of small nodules of less than $2 \mathrm{~cm}$ size, nodules deep within the gland and nodules arising from superior or inferior poles of lobes. Physical examination was able to detect only $21 \%$ of the 249 nodules detected by ultrasound in a large prospective study done by P. W. Wiestt et al. Evolution of high resolution ultrasound equipment has overcome these limitations and resulted in significant improvement in detection of these nodules 6 .

Although thyroid nodules can occur at any age, the maximum incidence of thyroid nodules is between 30 to 50 years ${ }^{7}$. This correlates with our study, in which $81.6 \%$ of patients were in $3^{\text {rd }}, 4^{\text {th }}$ and $5^{\text {th }}$ decades.

The solitary thyroid nodules show a significant predilection towards female sex with male to female ratio of 1:7 in our study, which was expected, as most of the diseases thyroid show female preponderance 8 .

Size of the nodule is not a reliable indicator to suggest benign or malignant nature of the nodule9. Small nodules of less than $1 \mathrm{~cm}$ size can also have malignant potential and can even have nodal or extranodal spread. In our study we found papillary carcinoma in a lesion of subcentimeter size. So, sonological features, rather than size alone are helpful in predicting the malignant nature of a nodule.

\section{Sonological criteria of assessment of nodules:}

A. Margins: Poorly defined, irregular, incomplete or microlobulated margins are in favour of malignancy, whereas sharp, completely well-defined margins indicate benign nature of nodules 4 . The margin is considered to be poorly defined when more than $50 \%$ of the margin is not clearly delineated. The previous studies reported that the sensitivity of this feature ranges from 8.3 to $84 \% \%^{4,5}$. However in our study, this feature got low sensitivity (33\%), but has high specificity $(75 \%)$.

B. Calcifications: They can be of two types; Microcalcifications and Macrocalcifications. Microcalcifications are seen as multiple punctuate bright echogenic foci of more than $2 \mathrm{~mm}$ size, usually without posterior acoustic shadowing. They are likely to represent psammoma bodies, which are characteristically seen in papillary carcinoma. So, the presence of microcalcification favours the possibility of malignancy in a given nodule. However, they should be differentiated from the calcification in benign cystic nodules, which typically contain posterior 'Comet tail' artefact. Macrocalcifications are of three types according to Kim et al. They can be a) Solitary calcifications (linear/curvilinear echogenic foci of more than $2 \mathrm{~mm}$ size within the nodule and are covering less than $1 / 3^{\text {rd }}$ of circumference of nodule). b) Eggshell calcification (curvilinear calcification covering more than $1 / 3^{\text {rd }}$ of circumference of nodule). c) Not-otherwise - specified (NOS) variety. Macrocalcification typically indicates benign nature of nodules ${ }^{10}$.

Intranodular microcalcification is the most reliable indicator of malignancy in thyroid nodules. This finding is closely associated with malignancy, with a reported incidence of 52 to $68 \%$ in literature. In the present study, the presence of microcalcifications has the highest specificity (97\%) and accuracy (85\%), when compared to other sonological parameters. This feature is in accordance with most of the studies in literature, which unanimously declared it, as the strongest criterion of malignancy ${ }^{11}$. 
C. Shape: Natural growth planes of a nodule in thyroid correspond to width on transverse axis. When the lesion is taller than wider in dimension, it indicates centrifugal aggressive growth, perpendicular to the natural growth plane, which is usual for malignancy. This feature has a high sensitivity and specificity for malignancy ${ }^{12}$. According to our study, although this feature has low sensitivity (46), it has high specificity (92.5).

D. Echogenicity: The echogenicity of the nodule is compared with the background gland parenchyma and hypoechogenicity of the nodule was considered to be in favour of malignancy ${ }^{11}$.The sensititivity and specificity of this feature in our study are $66.6 \%$ and $86 \%$ respectively.

There are few studies, which considered marked hypoechogenicity as a criterion to suggest malignancy, rather than just hypoechogenicity. A nodule is said to be markedly hypoechoic, if it has less echogenicity than the anterior strap muscle layer. This modification aids in increasing the specificity value, but results in poor sensitivity ${ }^{13}$.

E. Internal composition: Depending on the relative proportions of solid and cystic portions, the nodules can be completely solid, predominantly solid, completely or predominantly cystic. Most malignant nodules are completely or predominantly solid. The vice versa is not true (most solid nodules are benign), thereby resulting in low positive predictive value of this criterion ${ }^{14}$. Although this feature has high sensitivity (80\%), the positive predictive value $(27 \%)$ and diagnostic accuracy $(40.5 \%)$ are too low to consider this as a criterion to consider or rule out a nodule as malignant.

F. Peripheral halo: Complete, thin sonolucent halo indicates displaced blood vessels coursing around the lesion and is usually seen in benign nodules. Malignant nodules are reported to have incomplete thick irregular halo, which was thought to represent compressed normal tissue due to rapid growth of tumour 7 . The sensitivity and specificity of this feature are $60 \%$ and $46 \%$ respectively in our study.

G. Colour flow: It can be classified as 4types: type I: only peripheral flow, Type II predominantly peripheral flow with minimal central flow. Type III extensive internal flow with peripheral flow. Type IV central flow only. Nodules with predominantly central flow are likely to be malignant 15 . This feature has high sensitivity (80\%) but poor specificity (40\%) and high negative predictive value $(85,7 \%)$ in detecting malignant nodules in our study.

In addition to the above features, extra thyroidal spread to cervical lymph nodes is considered as a reliable feature of malignancy. Neck node involvement is independent of size of thyroid nodule and these nodes usually morphologically resemble the primary neoplasm. These metastatic nodes can be identified by loss of cortico-hilar distinction, eccentric cortical widening, L/T ratio (longitudinal/ transverse) of less than 1.5 and presence of cystic components or microcalcifications ${ }^{16}$.

The limitations of our study were this was a retrospective chart review study, wherein we had to depend on pre-recorded material. Furthermore the sample size is small.

CONCLUSION: Thyroid nodules can occur in all ages. High frequency ultrasound is of utmost importance in evaluation of thyroid nodules and in selecting the nodules, which need pathological examination. Nodules with taller than wide shape, hypoechogenicity, microcalcifications, absence of peripheral halo and internal vascularity are likely to have higher incidence of malignancy and must be investigated by FNAC, preferably ultrasound guided one. Irregular margin has relatively less 
diagnostic value in our study, when compared to other studies. Size is not a reliable criterion for characterization of thyroid nodule. The combination of the sonological features is more helpful in characterization of a thyroid nodule, rather than a single feature in isolation. Hypoechogenicity, microcalcifications, taller than wide shape if present, are the most reliable indicators of likelihood of malignant disease. When the patient is not having any of these sonological features suspicious of malignancy, one can save the patient from the cost and trauma of invasive diagnostic procedures.

The authors express their sincere gratitude to Dr S. N. Sahu, professor, Head of the Department of Radio-Diagnosis (Rtd) for his encouragement and valuable suggestions in this study.

\section{REFERENCES:}

1. Tan G H, Gharib H. Thyroid incidentalomas: management approaches to nonpalpable nodules discovered incidentally on thyroid imaging. Ann Intern Med 1997; 126: 226-31.

2. Brander A E, Viikinkoski V P, Nickles J I, Kivisaari L M. Importance of thyroid abnormalities detected at US screening: a 5 year follow-up. Radiology 2000; 215: 801-6.

3. Dorairajan N, Jayashree N. Solitary nodule of the thyroid and the role of fine needle aspiration cytology in diagnosis. J Indian Med Assoc 1996; 94(2): 50-2.

4. Frates MC, Benson CB, Charboneau JW, Cibas ES, Clark OH, Coleman BG, et al. Management of Thyroid Nodules Detected at US: society of Radiologists in ultrasound Consensus Conference Statement. Radiology 2005: 237; 794-800.

5. Manju Bala P, Ashita R, PJS Bhalla, Yachna S. Utility of gray-scale ultrasound to differentiate benign from malignant thyroid nodules.IJRI2012; 22 (1): 63-68.

6. P.W. Wiestt, M.F. Hartshoorne, P.D. Inskip, L.A.Crooks et al. Thyroid palpation versus high resolution thyroid ultrasonography in the detection of nodules. Journal of Ultrasound in Medicine, 1998, Vol 17, Issue 8, 487-496.

7. Solbiati L, Charboneau JW, Osti V, James EM, Hay ID. The Thyroid Gland. In: Wilson SR, Charboneau JW, Rumack CM, editors. Diagnostic Ultrasound. 3 rd ed. Missouri: Mosby, Elsevier Inc.; 2005. p. 735-70.

8. Vander JB, Gatson EA, Dawber TR. The significance of nontoxic thyroid nodules. Final report of a 15-year study of the incidence of thyroid malignancy. Ann Internal Med 1968; 69: 537-40.

9. Abay Taddesse, Abid Yaqub. Clinical, sonographic and cytological evaluation of small versus large thyroid nodules, J Pak Med Assoc; Vol. 61, No. 5, May 2011:466-469.

10. Kim MJ, Kim EK, Kwak JY, Park CS, Chung WY, Nam KH. Differentiation of thyroid nodules with macrocalcifications role of suspicious sonographic findings. J Ultrasound Med 2008; 27:1179.

11. Kim EK, Park CS, Chung WY, Oh KK, Kim DI, Lee JT, et al. New sonographic criteria for recommending fine-needle aspiration biopsy of nonpalpable solid nodules of the thyroid. AJR Am J Roentgenol 2002; 178:687-91.

12. Cappelli C, Castellano M, Pirola I, Gandossi E, De Martino E, Cumetti D, et al. Thyroid nodule shape suggests malignancy. Eur J Endocrinol 2006; 155:27-31.

13. Bonavita JA, Mayo J, Babb J, Bennett G, Oweity T, Macari M, et al. Pattern recognition of benign nodules at ultrasound of the thyroid: Which nodules can be left alone? AJR Am J Roentgenol 2009; 193:207-13.

14. Moon WJ, Jung SL, Lee JH, Na DG, Baek JH, Lee YH, et al. Benign and malignant thyroid nodules: US differentiation - multicenter retrospective study. Radiology 2008; 247:762-70. 


\section{ORIGINAL ARTICLE}

15. De Nicola H, Szejnfeld J, Logullo AF, Wolosker AM, Souza LR, Chiferi V Jr. Flow pattern and vascular resistive index as predictors of malignancy risk in thyroid follicular neoplasms.

J Ultrasound Med. 2005 Jul; 24(7):897-904.

16. Papini E, Guglielmi R, Bianchini A, Crescenzi A, Taccogna S, Nardi FF. Risk of malignancy in nonpalpable thyroid nodules: predictive value of ultrasound and colour Doppler features. J ClinEndocrinolMetab.2002May; 87(5):1941-6.

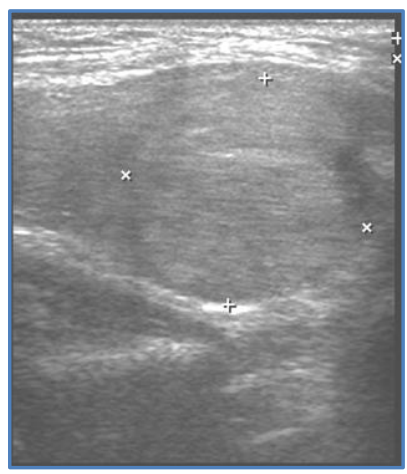

Image 1: A well defined hyperechoic nodule in left lobe of thyroid, with complete hypoechoic halo. Proved case of follicular adenoma on FNAC.

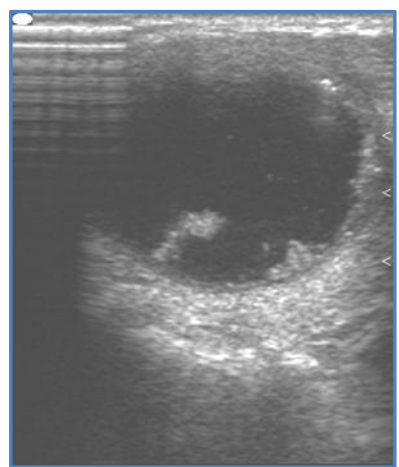

Image 2: A well defined predominantly cystic nodule in left lobe of thyroid, with calcification showing comet tail artifact (proved as colloid nodular goiter on FNAC).

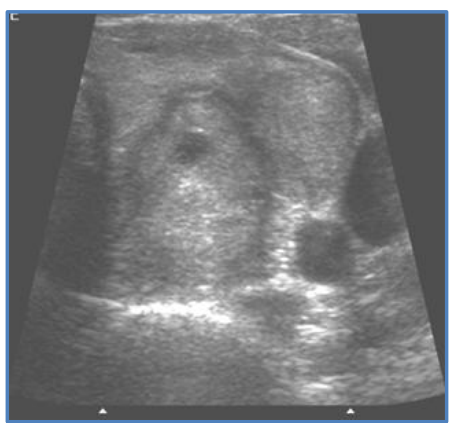

Image 3: An ill defined nodule in left lobe of thyroid, showing thick, incomplete halo(proved as follicular carcinoma on FNAC). 


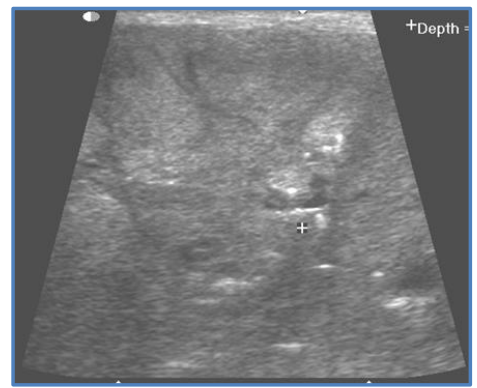

Image 4: An ill defined nodule in right lobe, showing microcalcifications (Proved as papillary carcinoma on FNAC)

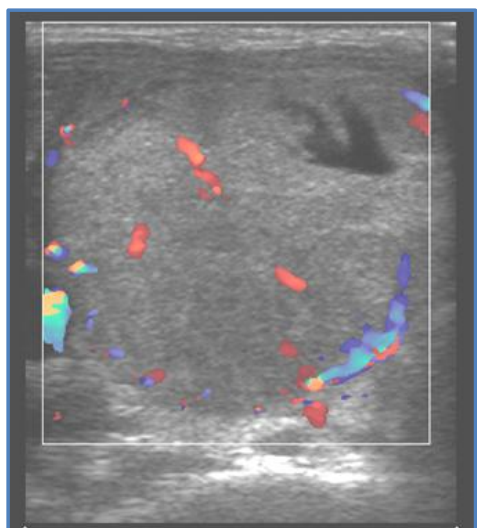

Image 5: A well defined nodule in left lobe of thyroid, showing incomplete halo and internal vascularity (proved as follicular carcinoma).

\section{AUTHORS:}

1. Madhavi Chamarthi

2. Abhilash S.

3. G. S. Kejriwal

\section{PARTICULARS OF CONTRIBUTORS:}

1. Assistant Professor, Department of RadioDiagnosis, Maharajah's Institute of Medical Sciences.

2. Post Graduate, Department of RadioDiagnosis, Maharajah's Institute of Medical Sciences.

3. Professor, Department of Radio-Diagnosis, Maharajah's Institute of Medical Sciences.

\section{NAME ADDRESS EMAIL ID OF THE} CORRESPONDING AUTHOR:

Dr. Madhavi Chamarthi, Quartr No. B-1,

Maharajah's Institute of Medical Sciences, Nellimarla Vizianagaram dt., Andhra Pradesh - 535217.

E-mail: chmadhavi_80@yahoo.com

Date of Submission: 19/12/2013. Date of Peer Review: 20/12/2013. Date of Acceptance: 11/01/2014. Date of Publishing: 25/02/2014. 